\title{
Governing and Monitoring the Digital Transformation: Assessing the Qatari Experience since 2003
}

\author{
Waleed Kamaleldin Mahmoud \\ Ali \\ Ministry of Transport and \\ Communication \\ wali@motc.gov.qa, \\ waleed.k.ali@gmail.com
}

\author{
Morten Meyerhoff Nielsen \\ United Nations University Operating \\ Unit on Policy-Driven Electronic \\ Governance \\ meyerhoff@unu.edu
}

\begin{abstract}
Qatar ranked second in the Arab region on the Government Electronic and Mobile Services Maturity Index 2020, $10^{\text {th }}$ in Western Asia and $66^{\text {th }}$ on the UNDESA E-Government Development Index for the same year. Performing well above the global average on most international indexes what are the Qatari lessons to the measurement of the digital transformation of the public sector? This paper focus on three interrelated enablers of digital transformation that is Qatar's approach to governance, inter-government cooperation, and the monitoring and measurement of benefit realization. The analysis finds that the formulation of digital government strategy as well as the monitoring of the implementation of the initiatives follow a joint-governmental approach. This results in a degree of joint ownership and have accelerated IT and technology enabled public sector services production and delivery. In relation to monitoring, measurement and benefit realization the picture is less clear. While there is evidence of Qatar applying measurable success and key performance criteria in relation to the Qatar Digital Government strategy 2020 and applies ex ante, ex post evaluation of strategic projects the results are not publicly available at the time of writing. While past research in countries like Denmark and the UK shows that standardization of the process and close monitoring can reduce the failure factors, this paper only find limited evidence of this in the case of Qatar and is an area of improvement.
\end{abstract}

\section{CCS CONCEPTS}

- Applied computing • Computers in other domains • Computing in government $\bullet$ E-government

\footnotetext{
Permission to make digital or hard copies of all or part of this work for personal or classroom use is granted without fee provided that copies are not made or distributed for profit or commercial advantage and that copies bear this notice and the full citation on the first page. Copyrights for components of this work owned by others than ACM must be honored. Abstracting with credit is permitted. To copy otherwise, or republish, to post on servers or to redistribute to lists, requires prior specific permission and/or a fee. Request permissions from permissions@acm.org.

ICEGOV 2021, October 06-08, 2021, Athens, Greece

(c) 2021 Association for Computing Machinery.

ACM ISBN 978-1-4503-9011-8/21/10...\$15.00

https://doi.org/10.1145/3494193.3494227
}

\section{KEYWORDS}

eGovernment, governance, intergovernmental cooperation, strategy, benefit realization, key performance indicators, Qatar

\section{ACM Reference format:}

Waleed Kamaleldin Mahmoud Ali and Morten Meyerhoff Nielsen. 2021. Governing and Monitoring the Digital Transformation: Assessing the Qatari Experience since 2003. In 14th International Conference on Theory and Practice of Electronic Governance (ICEGOV 2021), October 06-08, 2021, Athens, Greece. ACM, New York, NY, USA, 8 pages. https://doi.org/10.1145/3494193.3494227

\section{Introduction}

The process of digitizing public services began in earnest two decades ago as a step toward improve the efficiencies and effectiveness of the public sector service production and service delivery modernizing governmental systems. In this context Information Communication Technology (ICT) can be actively used to underpin the global Sustainable Development Goals (SDGs) in a number of ways. Productivity gains, administrative burden reduction in relation to the public service production and underpin the Agenda in a number of ways [2, 6, 14, 20]. For instance, productivity growth within the public sector may release resources to promote other development goals (SDG 8). Efficient and effective use of technology in the back office facilitate a more transparent and inclusive society, sustainable economic growth, and employment and decent work for all (SDG 8 and SDG 16)[28, 47, 49]. The potential is amplified if ICT use is combined with regulatory, organizational and process reengineering [6, 20,36]. Technology is an integral part of a resilient public sector infrastructure and can help foster sustainable innovation and value creation in the public and private sectors as well as society at large (SDG 9) [1, 2, 14]. Similarly, technology can be used to effectively plan, address the spread and treatment of communicable diseases, environmental and economic disruptions $[2,8,14]$ As the digital transformation have accelerated [10], not least in light of the ongoing Covid-19 pandemic [48], digital transformation strategies are fast becoming the key instrument in shaping the innovative application of ICT to modernize the public sector. Some countries have been more successful than others in their digital 
government transformation initiatives due to performance measuring [34, 39, 40]. Many interrelated factors are at play when it comes to public sector technology use: Technology itself; history, culture and socio-economic factors; the way government is organized and operates; legal traditions; governance and inter-governmental models; risk adversity plus societal trust in government and institutions. Of these, this paper will focus on three key elements in the Qatari context and what lessons can be drawn from the Qatari approach to governance, cooperation and benefit realization.

\section{Analysis}

Qualitative research is highlighted as "the study of the nature of phenomena", including "their quality, different manifestations, the context in which they appear or the perspectives from which they can be perceived", but discounting "their range, frequency, and place in an objectively determined chain of cause and effect" [42]. This conventional description can be accompanied by a more practical rule of thumb: qualitative research commonly includes information in form of words rather than numbers [43].

This study has used document analysis as its main form of research design. Like other qualitative research methods, document analysis as a methodical procedure for examining or assessing documents - both printed and electronic. Specifically, the document analysis involved exploring and understanding specific content and data to gain understanding to develop a practical and theoretical understanding of a given issue or phenomena [7, 44, 45], Referring to documents as 'social facts', created and shared in a socially organized ways between researchers the objective of the document analysis is to further the understanding and gain insights into to a given topic [45, $\mathrm{p}$. 47], in this case the Qatari approach and experience in relation to the governance and monitoring of the digital transformation since 2003.

Documents used for systematic evaluation of this study take a variety of forms, including advertisements; agendas, attendance registers, and minutes of meetings; manuals; background papers; books and brochures; diaries and journals society offices, and organizational or institutional files. For our study past research but particularly official government documents provide an overview the socio-economic context of Qatar, its strategic focus on technology and its application within the public sector and society. In this study, analytic procedure entailed finding, selecting, appraising (making sense of), and synthesizing data contained in various documents. The document analysis was organized into major themes, categories, and examples specifically used for the content analysis of this study [27]. In practice, content not specifically addressing the governance and monitoring issues, or which was not indirectly related was omitted from the study's analysis. The final documents and document extracts analysed all bear witness to past and present issues related to the digital transformation of Qatar, relevant contextual factors found to be of relevance in past research (e.g. socio-economic factors), In doing so the document analysis provided the contextual background as well as historical insight. Information and insight which help develop an understand of the historical roots and specific issues in the current progress of government management and can indicate the conditions impacting the digital transformation phenomena, and specifically the role of governance and monitoring, being explored by this study, in the Qatari context [9].

\section{THE QATARI APPROACH}

The successful digital transformation of the public sector is based on the interplay between technology (i.e., backend service producing systems and frontend service interfaces and services) and governance mechanisms [3]. While Baldwin \& Woodard [3] argue that public authorities keep a relatively high level of control to secure public values, Klievink et. al. emphasis the need to balance autonomy and control, but in combination with formal business models with collaborative processes [10].

In the analysis of Qatar, this paper differentiates between eGovernance and eGovernment. eGovernance encompass all processes of governing and decisions made in relation IT and technology use, whether undertaken by a government, market or network, whether over a family, tribe, formal or informal organization or territory and whether through laws, norms, power or language [21]. eGovernment is the use of ICT and its application by government for the provision of information and public services to the people [21], that is the daily implementation of the decisions made as part of the governance of a country or a single organisation.

Qatar is by population and geographical size a small, but high-income country. The country heavily depended on liquid natural gas exports and is as a result in the process of diversifying its economy. Knowledge based economic, society development, finance and establishing tourism industry were the main areas in the strategy to move towards non-energy resources. Qatar is also building a legacy for future generations through the innovative developments and infrastructure undergoing as the perpetration to host the FIFA World Cup ${ }^{\mathrm{TM}}$ tournament for the year 2022 .

Table 1: Socio-economic data for Qatar, 2020 [12, 24, 32, 52]

\begin{tabular}{ll}
\hline Items & \\
\hline Population (millions) & $2,684,329$ \\
Population growth (annual \%) & 2.1 \\
Territorial size & 11,521 square kilometers. \\
Urbanization & $99.23 \%$ \\
Population density & 242.1 \\
Official language & Arabic \\
GDP (billion USD) & 183.33 \\
GDP per capita (USD) & $62,088.06$ \\
\hline
\end{tabular}

Analysing relevant policy documents and past research on ICT use in the Qatari public sector, it becomes clear that the approach to governance have not been specifically analysed. Closet to the topic of this paper, is Benmansour et. al [8] exploration of local governance and eServices in Qatar finding in part that little have been done to measure the impact of ICT 
investments. By comparison, Al-Refai [4] have looked at how eGovernment stimulate economic growth in the Gulf Cooperation Council (GCC) countries from an empirical perspective. Using UNDEA E-Government Development Index (EGDI) and World Bank Ease of Doing Business (EODB) data the link between economic growth and use of technology is confirmed, particularly in relation to technical infrastructure and online services. The result for Qatar is nonetheless mixed, perhaps a result of the varied performance of Qatar on the EGDI and EODB in the period. Research by Weerakkody et. al. explored eGovernment in the state of Qatar in relation to benefits (to end-users), challenges and complexities of a developing economy [50, 51]. El-Kassem et. al. [19] used path analysis (based on a user-survey of $1700+$ respondents) to analyse factors influencing the adoption of mobile services in Qatar. The results found support for the Technology Acceptance Model (TAM) including influence of awareness, trust and perceived usefulness and ease of use as driving factors. Al-Kubisi [2] takes a quantitative approach when measuring citizens and residents' satisfaction of online services and level of transparency in Qatar. Based on questionnaire, respondents indicates that financial disclosure and easy to understand legislation would foster transparency while more classical transactional services and information on traffic, accidents etc. are seen to provide value to individuals on a daily basis.

Analysing relevant Qatari policy documents, it becomes clear that the approach to governance has evolved over time. The governance and management model have been the subject of review with each passing eGovernment strategy and has been adjusted based on the lessons learned. Two key periods since 2003 is identifiable. Between 2003-2013, the first eGovernment strategy focused on underpinning the Qatari backend service production and frontend service delivery ecosystems. Key initiatives include Qatar's integrated government program launched in 2006 with the aim to enhanced government services to public and businesses, Hukoomi the Qatar's official eGovernment portal in 2008, and in 2013 setting up the national digital government steering committee to guide the development and implementation of nationwide eGovernment strategy [24, 32]. In 2014, preparation of the second eGovernment strategy was initiated and resulted in the Qatar Digital Government (QDG) Strategy 2020 launched in 2015 [35]. To compliment the QDG Strategy the Qatar Smart Program “Tasmu” was launched in 2017 with a focus on turning the capital city Doha into a smart city [46]. Key strategic initiatives in the period included the launch of the national authentication system (i.e. electronic identity /electronic signature (eID / eSignature)) to enable a higher degree of online service use, and open data portal in 2019 to promote government openness and innovation development $[24,32]$.

Qatar's strategic focus follows a classical trajectory in its focus on simple and secure digital services connecting efficient Government. With its initial focus on infrastructure, enabling backend systems and registries, national one-stop portal, the focus has moved to electronic identity management, capacity and skills development to drive the digital transformation and optimise the associated benefits from ICT investments [34, 37]. This is evident in the structure and focus of the QDG Strategy 2020 that it not only builds on the previous strategic period and link to other strategies like the second National Development Plan and the Qatar's Vision 2030 [21, 31, 35]. In analysing the strategy, it is evident that Qatar is inspired by the vision, objectives and governance seen in countries like Singapore, Republic of Korea, Estonia, Australia and not least Denmark in its approach to user-centricity and its shift to digital-by-default $[11,33,34]$.

While Qatar was ranked second in the Arab region on the Government Electronic and Mobile Services Maturity Index 2020 [53], the country ranked $10^{\text {th }}$ in Western Asia and $66^{\text {th }}$ globally on the UNDESA EGDI for the same year [1]. The positive impact of the digital transformation strategies since 2003 is reflected in the country's performance on the biannual UNDESA eGovernment Readiness (EGDI) in Figure $1 .^{1}$ Moving from an Online Service Index value well below the global average in 2003, the first focus strategic period (2003-2013) established a basic service production (backend) and service delivery (frontend) ecosystem in Qatar, with the country performing well above the global average from 2005 onwards. The launch of Hukoomi one stop portal in 2008 and subsequent enrichment of its content and launch of transactional online services from 2010 onwards is illustrated by the improved OSI value in 2012. The stagnated OSI value is a result of the missing core shared services, for instance national electronic authentication system (i.e. eID and eSignature) which was only launched in 2019. Since the Qatari performance have stagnated. even regressed since 2014 in relation to global performance,[1] as a result of two interconnected factors: Relative lower pace of Qatari service improvement compared to its global peers, a need to move from a classical first generation eGovernment approach to digitisation to a more innovative smart and whole of government approach. Similarly, the comparatively late focus on electronic identity management in Qatar constitutes a challenge in two ways: First, the lack of a key enabler for secure online authentication have limited the benefits of existing service delivery platforms; Second, the 2020 QDG Strategy's success criteria of $80 \%$ of service delivery being online this has been difficult to achieve as planned due to the variation of ICT maturity level of different entities in the government and subsequent need to encourage citizens, residents and business to change their behavior [35]. Future strategies would benefit from a closer alignment between strategic cycles and also from focusing on key enabling elements like the legal and regulatory framework to optimise the use of ICT in process simplification, build on the established key infrastructure for identity management and data exchange and reuse between entities and the compliance with standards for interoperability. Holding up national ambitions to the successful initiatives and lessons learned in other countries should continue as it has benefitted Qatar so far. With the country seemingly being inspired by global leaders such as Australia, Denmark,

${ }^{1}$ Note: UNDEA's EGDI is chosen as it covers a longer period than ESCWAS' assessment. 
Republic of Korea and the United Kingdom (UK) it would beneficial to also apply the ex ante and ex post monitoring, measurement and benefit realisation models seen in these countries [33, 34, 40] which is also reflected in past recommendations by organisations such as the OECD [39].

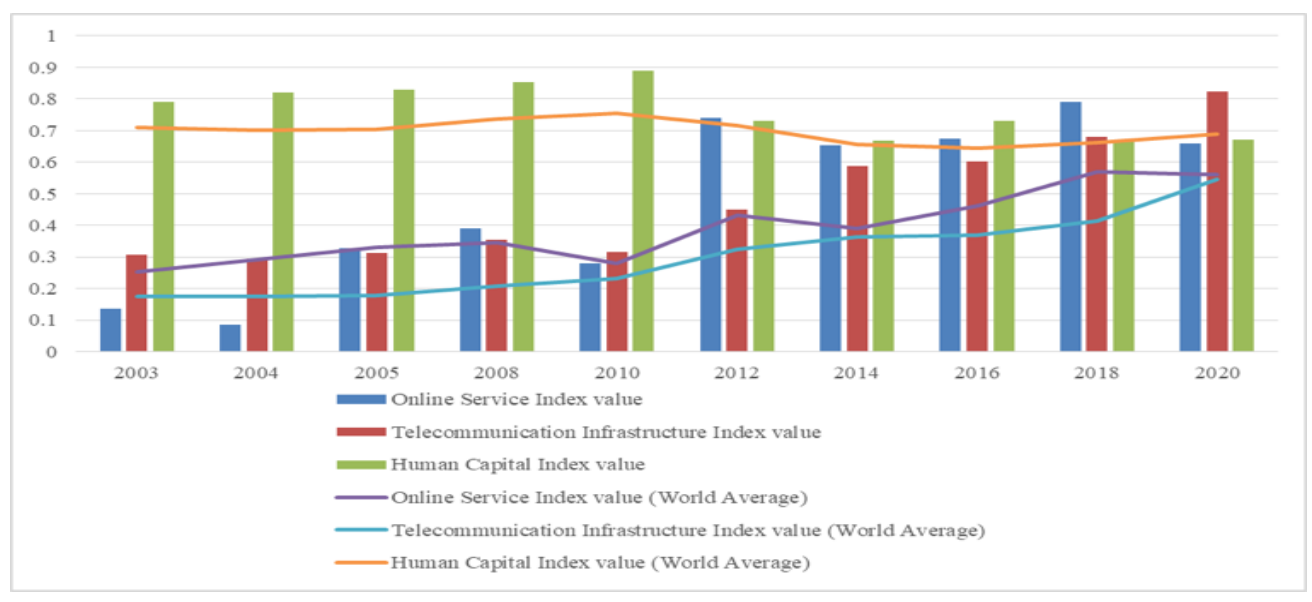

Figure 1: EGDI sub-indexes for Qatar and the world average, 2003-2020 [1]

While the OSI is an indication of the availability of information and transactional services online [1], the World Banks, Ease of Doing Business Index (EODB) $[16,52]$ in Figure 2 illustrate the outcomes in relation to relative level of bureaucracy faced by businesses, speed and quality of public services $[19,51]$. Key to the Qatari approach have been to learn from its focus on citizens and residents during its initial period of digitisation and apply this to business services [19, 51]. The single service window initiative for investors [3] was launched in 2019 (the ALNadeeb portal) to integrate number of government entities in one-stop-shop for issuance of establishment registration, and the electronic documentation of Memorandum of Association. This was followed by launching Dhareeba tax portal [13]. The combination of ICT enabled modernisation service production and delivery have during the first and second strategic periods also resulted in a reduction in the bureaucracy faced by individuals and business. These initiatives have aimed to simplify internal backend process and apply a digital by default principle for service delivery. To facilitate start-ups and attract foreign direct investments, the
ALNadeeb portal enabled the online creation and management custom clearance documents and information about importing to Qatar. The key aim was to facilitate economic diversification as specified in the Qatar 2030 Vision [21] and even branding Qatar internationally [41]. While the impact of these initiatives to facilitate economic diversification and attract foreign investment is still unclear [5, 41], the process simplification and digitisation efforts have resulted in an improved Qatar's relative attractiveness as a business destination as the World Bank [14] EODB score for Qatar improved by 32 points between 2012 and 2020 and by 2.9 point on the regional sub-index. It is showed in areas like obtaining electricity connection and property registration process via online channels. While Qatar have followed a classical trajectory in relation to the application of ICT in service production and delivery, its initial focus on citizen and residents is different from most other countries, which have tended to focus on the business community first. The cause of this is not clear as Qatar in the period have had a key focus on national economic development and diversification [21, 31].

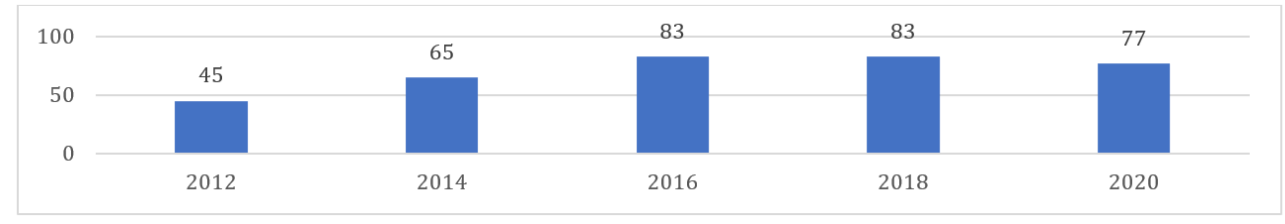

Figure 2: Ease of Doing Business score for Qatar and the world average, 2012-2020 [14, 52]

\subsection{GOVERNANCE AND COOPERATION}

Since 2003 the Qatari approach to governance and intergovernmental cooperation has changes. While the Ministry of Transport and Communication (MoTC) have remained the responsible authority for ICT and the digital transformation of the public sector and society at large, the initial 2003-2013 period saw only sporadic coordination and collaboration during the implementation of the first national strategy. The QDG Strategy 2020 marks a clear shift towards a more formalized approach to 
the governance and cooperation [35]. The QGD Strategy 2020 vision aimed at transforming the relationship between the public sector and the public in general and to benefit individuals and businesses though efficient, effective and transparent online service offers [35]. This was in part driven by suggestions that user-centricity and perceived quality of online service offers were not on par with regional and local good practice [2]. To adopt a user-centric whole-of-government approach, support from Council of Ministers in the area of legislative amendment to allow changes and openness in the government services and data was required. Summarised in Table 2 and Figure 3 the shift in the approach to governance and intergovernmental cooperation is illustrated by the establishment of the Digital Government Steering Committee (DGSC) to support the Cabinet of Ministers in their work to establish the Qatari vision for eGovernment and the digital transformation of the public sector in particular $[22,35]$.

At the strategic level the DGSC is supported by the Strategic Management Office (SMO) within the MoTC. The DGSC and SMO in turn facilitate the consultation with individual ministries and authorities to develop the strategy and action plans required to achieve the governments vision. While the different initiatives are the responsibility of individual line ministries and agencies, the SMO is on the operational level the SMO is responsible for coordinating and monitoring the implementation of the strategy and action plan. This included developing the specific indicators to monitoring individual initiatives. The SMO review, approve and correct the path in the implementation of projects master plan. The implementation and policy setting role in the Qatari model is entity based expect for the government shared services and polices that been implemented by eGovernment programs and standards department at the MoTC, the Mada center the assistive technology center in Qatar for policies related to assistive technology and inclusion, Qatar Communication Regularity Authority, QCERT and shared government wide to accelerate development and release of different sectors services electronically. This is also supported by the ICT Review Committee which monitor the procurement of ICT solutions across the Qatari government. The objective is to avoid unnecessary spending on duplicate solutions and to ensure that the action plan is implemented on time and on budget. In case of unexpected difficulties, a lack of coordination or compliance with the strategic framework and the action plan, the SMO may escalate issues to the DGSC. The DGSC and the SMO both have representation of all twelve Qatari ministries [22, 35].

Table 2: Qatar's governance and coordination model since 2015 [22]

\begin{tabular}{lll}
\hline & Co-ordination of strategy implementation & $\begin{array}{l}\text { Wider co-ordination for the digital } \\
\text { transformation }\end{array}$ \\
\hline Vision & $\begin{array}{l}\text { Cabinet of ministers supported by Digital } \\
\text { Government Steering Committee (DGSC). }\end{array}$ & DGSC facilitated consultation. \\
\hline
\end{tabular}

Strategy

Implementation of action plans and monitoring

Implementation of individual initiatives

The shift in the Qatari approach to governance and collaboration has been away from internal stakeholder from in different entities government wide (Figure 3, next page) to include private sector. Similarly, the launch of the Tasmu consultation portal is an example of this shift [46]. As an assessment of the QDG 2020 strategy was not available at the time of writing it is not clear if some findings of Benmansour et. al. has been adequately addressed [8].

The governance module seems to have been effective in setting strategic vision, objective and monitoring the strategy implementation. However, this model can be improved to accommodate other stakeholders form the ecosystem to help with ICT centric innovation national indicatives [22, 35]. Despite ongoing formal and information consultation and the launch of the Tasmu initiative to underpin this with both public and nonDGSC for escalation.
DGSC and SMO facilitated consultation with individual ministries and authorities.

MoTC but specifically the SMO. Monitoring and procurement of ICT solution and initiatives by ICT Review Committee

Informally. public sector stakeholders [22,46], authorities seem to limit their engagement due to resource constraints. The impact of Tasmu on the level of engagement in relation to strategies for the digital transformation of the public sector is still to be analyzed as it was launched in 2017 [46] and the follow-up on QDS 2020 is currently ongoing. Stakeholder involvement in the Qatari governance model is illustrated in Figure 4. 


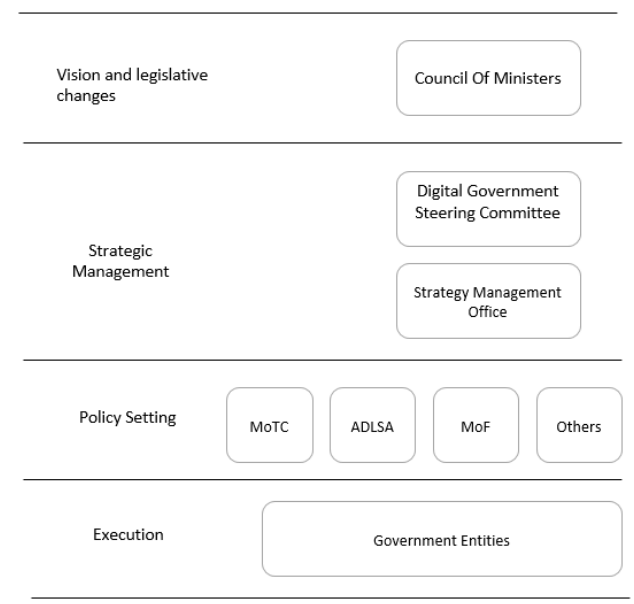

Figure 3: Organigram of the eGovernment strategy, Portfolio Steering Committee and project steering committee in Qatar 2015-2020 (Authors)

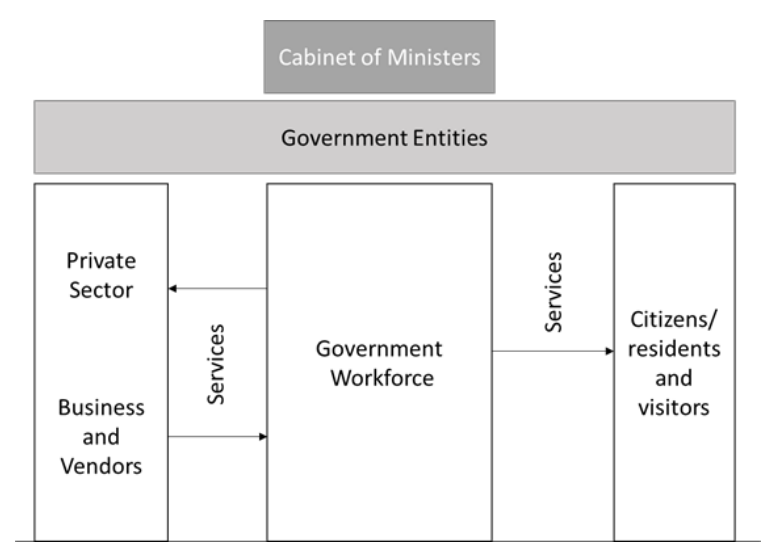

Figure 4: Stakeholders in the Qatari governance and coordination model (Authors)

\subsection{MONITORING, MEASUREMENT AND BENEFIT REALISATION}

McKinsey and Oxford University estimated that $64 \%$ public and private sector ICT projects exceeding $€ 10$ million exceed their original budgets and $78 \%$ are delayed [30]. While the shift in the Qatari strategic focus show have resulted in majority of citizens and residents having high level of satisfaction when interacting with digital governmental services as seen in Al-Kubisi [2] research, it is unclear if the disconnect between the monitoring, measurement and benefit realisation at the project and operational level identified by Benmansour et al. [8] have been adequately addressed.

In fact, the monitoring level is disconnected from the steering committee monitoring level despite the involvement of different entities in the committee. The committee interfere only when there is an escalation or roadblocks in integration across entities. Lack of collaboration in projects and polices cross entities delay projects implementation and affecting the adoption of new online services. Majority of the project on QDG 2020 master plan were delivered successfully but the transformation in public sector electronic services is hard to measure as these initiatives were implemented in different entities and some are not fully integrated [35]. This might be overcome by introducing standardized project management best practice across government entities and starting Centre of Excellences to support in the following standardized procedures across government to plan, manage, and deliver projects that connected to strategic objective and measure the transformation and benefit realisation.

The use of structured project management models and systematic review of projects is not unique to the Qatari approach to ICT initiative and the digital transformation of the public sector, the structured approach. In fact, countries like the Denmark, UK and The Netherlands have similarly models in place and UAE makes use of change management and innovation models to ensure that risks and cost-benefits are addressed from the onset [15, 23, 25, 29, 33, 38].

\section{CONCLUSION}

In conclusion, the strength of Qatar's governance model is in the level of coordination, consensus seeking, and collaborative approach taken to digitisation of the Qatari public sector are clearly demonstrated by the increasing number of government digital services that depend on the government shared services provided by QDG 2020 strategy. While formal and informal consultations are emerging as the norm for new eGovernment strategies (especially with the QDG 2020 strategy), it is unfortunately the private sector, academia, and select end-user groups that are not formally part of the governance model, as this could help ensure a more holistic approach to ICT use in public administration and focus, including breaking down organizational barriers to the benefit of citizens and businesses. Similarly, consultation and transparency for new strategies, and particularly on the envisaged focus and outcomes of action plan initiatives, could be strengthened in relation to nongovernmental stakeholders, including the private sector and academia. This is achievable if building on the existing mandate of MoTC, including private sector, society and expert community though in the governance structure or by increasing the proactive consultation with relevant stakeholders (e.g. though an pariticipation and consultation portal).

While the link between goals and KPIs in the strategy and individual initiatives help authorities to focus their attention to benefit realisation, the alignment of the strategic focus, action plans and the IT-project and business case models is in Qatar to be clarified and explained further to the workforce executing individual project at entities level. This can increase sense of ownership and accountability to achieve strategic KPIs. In fact the monitoring and evaluating in ex ante and ex post approach is currently the main weakness identified in the Qatari approach. While strategic initiatives and IT projects across government are evaluated and approved by review committee reduce duplication and continues monitoring control risks and failure factors it is not clear if strategic success criteria's are links between national 
strategies like Qatar Vision 2030, eGovernment and digital government strategies, the individual project and even the operational level as recommended by the likes of the OECD [39] and seen amongst global leaders like Australia, Denmark, Republic of Korea and the UK [33, 35, 41].

While historic and cultural context matters, there are five key lessons that other countries can learn from the Qatari approach. First, the link between vision, strategy, action plans, initiative goals and outcomes, although Qatar itself would benefit if strengthen in this further domestically as indirectly proposed by Benmansour et. al [8]. This had a positive effect in overcoming some of the challenges discussed by Weerakkody \& Al-Shafi [51] in Qatar and increase the country's global performance on the ESCWA, UNDESA and World Bank benchmarks [14, 17, 18, 54].

Second, setting the strategic direction across all of government and ensuing wide political support minimise resource intensive the stop-start's and zig-zag's in the strategic vision of the digital transformation. This is potentially also the reason for the mixed performance of Qatar in Al-Refia's [4] empirical analysis of the six Gulf Cooperation Council countries uses of ICT in relation to economic growth in the period. In Qatar experiences have to date highlighted that the various public sector entities and staff share the same vision that and working towards achieving the same strategic goals which reflected the maturity of the services provided and result in placing the country in the second place among Arab states on the ESCWA 2020 GEMS Index [54] and improved performance on both the UNDESA and World Bank benchmarks in recent years $[12,14,15,48]$.

Third, strong and recognised mandates when collaboration breaks down or if consensus cannot be reached are seen as important. In Qatar the digital government steering committee oversight and ensure collaboration between government entities and resolving any issues related to silos. The impact of the changes in approach since the QDG 2020 strategy is still not evident as an ex-ante - ex-post assessment in relation to the strategic targets is not yet available. On a theoretical level it may nonetheless be speculated that the alignment with global good practice and recommendations made by the likes of the OECD [39] should cetris paribus be positive.

Fourth, while steering, programme and project committees are not unique to Qatar, the experiences emphasis that reviewing and approving country wide IT projects ex ante to ensure alignment with QDG strategy, close monitoring by the SMO, and periodic assessment and evaluation of the outcomes against the goals. Resulted in laying the foundations to start the implementation and benefit realization, moving forward, and keeping Qatar digital government on track.

Fifth, linking strategic and operational KPIs is essential as is the continues assessment and improvement cycles between each strategic period is good project management in any national and organisational context. The Qatari approach is to have a strategic KPIs, but the linkage to operational KPIs is not clear and need to be aligned with initiatives and projects KPIs - point also made by Benmansour et. al [8] who found that little have been done to measure the impact of ICT investments when explore local governance and eServices in Qatar. This supports the conclusions of Klievink et. al. [26], the OECD [39] and those of Jordanoski \& Meyerhoff Nielsen of in relation to Australia, Denmark, the Republic of Korea and the UK [33, 35, 41].

\section{ACKNOWLEDGMENTS}

This article partially based on research carried out by the authors in connection with the "Measuring at the margins: A global framework for digital inclusion" Project for the Digital Future Society. The article is the result of the project "SmartEGOV: Harnessing EGOV for Smart Governance (Foundations, methods, Tools)/NORTE-01-0145-FEDER-000037”, supported by Norte Portugal Regional Operational Programme (NORTE 2020), under the PORTUGAL 2020 Partnership Agreement, through the European Regional Development Fund (EFDR). It was also supported in part by the European Commission (OpenGovIntelligence H2020 grant 693849), and Estonian Research Council (PUT773, PUT1361).

Disclaimer: The opinions in this paper does not necessarily reflect the opinion of the Government of Qatar or the Ministry of Transport and Communication.

\section{REFERENCES}

[1] UNDSA - United Nations Department of Economic and Social Affairs. 2016. EGovernment Readiness Survey Database. United Nations.

[2] Al-Kubisi, A.S. 2020. Measuring Citizens Satisfaction of E-Government and Transparency in the State of Qatar. International fournal of Innovative Science and Research Technology. 5, 10 (2020), 310-314.

[3] ALNadeeb investor.se.gov.qa: https://investor.sw.gov.qa/wps/portal/investors/aboutus/!ut/p/z1/04_Sj9CPykssy0xPLMnMz0vMAfIjo8zivfxNXA393Q38LULDjAwC nZ1MgxzdLYxNwsz1w_Ep8Hc01I8iRr8BDuBoQFh_FD4IYBeAFeCxwks_Kj0nP wniXce8JGOLdP2ootS01KLUIr3SIqBwRklJQbGVqoGqQXl5uV56fn56Tqpecn6u qgE2LRn5xSX6E.

[4] Al-Refai, M.S. 2020. The impact of e-government on economic growth in GCC countries. International Review. 1-2 (2020), 18-26.

[5] Al-Yafi, K. et al. 2016. A user-centric evaluation of e-government services in the GCC region: Case of state of Qatar. International fournal of Electronic Government $\quad$ Research. $12, \quad 4 \quad$ (2016), $15-34$. DOI:https://doi.org/10.4018/IJEGR.2016100102.

[6] Arendsen, R. et al. 2014. Does e-government reduce the administrative burden of businesses? An assessment of business-to-government systems usage in the Netherlands. Government Information Quarterly. 31, 1 (Jan. 2014), 160-169. DOI:https://doi.org/10.1016/j.giq.2013.09.002.

[7] Atkinson, P. and Silverman, D. 1997. Kundera's Immortality: The interview society and the invention of the self. Qualitative Inquiry. 3, 3 (1997), 304-325.

[8] Benmansour, N.A. et al. 2019. Exploring local governance and e-services in Qatar. International Journal of Public Administration in the Digital Age. 6, 4 (2019), 1-13. DOI:https://doi.org/10.4018/IJPADA.2019100101.

[9] Bowen, G.A. 2009. Document analysis as a qualitative research method. Qualitative Research fournal. 9, 2 (2009), 27-40.

[10] Brynjolfsson, E. and McAfee, A. 2012. Race Against The Machine: How The Digital Revolution Is Accelerating Innovation, Driving Productivity, and Irreversibly Transforming Employment and The Economy.

[11] Cepilovs, A. and Duenas-Cid, D. 2020. E-Estonia as a role model? Some general considerations and applicability in France . Drivers and enablers of egovernment implementation. La France des 13 Régions, un réforme aboutie? A Granero, ed. L'Harmatta. 10.

[12] Climate Country Scorecard: Qatar: 2020. https://epi.yale.edu/epiresults/2020/country/qat. Accessed: 2021-04-10.

[13] Dhareebe Tax Portal: 2021. https://dhareeba.gov.qa/sap/bc/ui5_ui5/sap/zmcf_welcome/index.html?sapclient=100;/sap/bc/webdynpro/sap/. Accessed: 2021-04-10.

[14] Doing Business 2020: Qatar's Ambitious Reforms Improve its Ranking: 2019 https://www.worldbank.org/en/news/press-release/2019/10/24/doingbusiness-2020-qatars-ambitious-reforms-improve-its-ranking. Accessed: 202104-10.

[15] DTMC - Dubai The Model Centre 2012. Dubai Model for Government Services. 
[16] Ease of Doing Business rankings: 2019.

[17] Ease of doing business: World Bank Open Data: 2020.

[18] E-Government Readiness Survey Database: 2018. \%7BUNDESA - United Nations Department of Economic and Social Affairs, 2016 \#778\%7D. Accessed: 2018-11-16.

[19] El-Kassem, R.C. et al. 2020. Path Analytic Investigation of the Intention to Adopt E-government Services through Mobile Applications in Qatar (Tam Revisited). International fournal of Advanced Research in Engineering and Technology. 11, 6 (2020).

[20] Gallo, C. et al. 2014. Study on eGovernment and the Reduction of Administrative Burden. European Commission.

[21] General Secretariat For Development Planning 2008. Qatar National Vision 2030.

[22] Governance: 2021. https://motc.gov.qa/en/qatar-digitalgovernment/governance. Accessed: 2021-04-10.

[23] Heeks, R. 2006. Understanding and measuring eGovernment: international benchmarking studies. UNDESA workshop,"E-Participation and EGovernment: Understanding the Present and Creating the Future", Budapest, Hungary. (2006), 27-28.

[24] hukoomi.gov.qa: 2021. https://hukoomi.gov.qa/en/about-qatar/about-qatar\#. Accessed: 2021-04-10.

[25] Kildebogaard, J. 2014. Her er statens problemer med it-projekter - og succeserne. Version2,.

[26] Klievink, B. et al. 2016. The collaborative realization of public values and business goals: Governance and infrastructure of public-private information platforms. Government Information Quarterly. 33, 1 (2016), 67-79.

[27] Labuschagne, A. 2003. Qualitative research: Airy fairy or fundamental. The qualitative report. 8,1 (2003), 100-103.

[28] Leitner, C. et al. 2003. eGovernment in Europe: The State of Affairs.

[29] Lovkrav til it-projekter i staten: 2018 https://digst.dk/styring/projektstyring/statens-it-projektmodel/lovkrav/. Accessed: 2018-11-16.

[30] Mckinsey, D. et al. 2012. Delivering large-scale IT projects on time, on budget, and on value. Digital McKinsey.

[31] MDPS - Ministry of Development Planning and Statistics 2018. Qatar Second National Development Strategy 2018-2022.

[32] Media Center: 2021.

[33] Meyerhoff Nielsen, M. 2019. Governance lessons from Denmark's digital transformation. Proceedings of the 20th Annual International Conference on Digital Government Research (2019), 456-461.

[34] Meyerhoff Nielsen, M. and Jordanoski, Z. 2020. Digital transformation, governance and coordination models: A comparative study of Australia, Denmark and the Republic of Korea. dg.o '20: The 21st Annual International Conference on Digital Government Research (New York, 2020), 285-293.

[35] MoTC - Ministry of Transport and Communications 2013. Qatar e-Government 2020 Strategy.

[36] Nielsen, M.M. et al. 2017. Administrative burden reduction over time: Literature review, trends and gap analysis. ACM International Conference Proceeding Series (2017)
[37] Nielsen, M.M. 2020. The Demise of eGovernment Maturity Models: Framework and Case Studies. Tallinn University of Technology Press.

[38] Obi, T. 2017. WASEDA - IAC International e-Government Index.

[39] OECD 2014. Recommendation of the Council on Digital Government Strategies 15 July 2014 - C(2014)88. OECD.

[40] Ozols, G. and Meyerhoff Nielsen, M. 2018. Connected Government Approach for Customer-centric Public Service Delivery: Comparing strategic, governance and technological aspects in Latvia, Denmark and the United Kingdom.

[41] Peterson, J.E. 2006. Qatar and the world: Branding for a micro-state. The Middle East fournal. (2006), 732-748.

[42] Philipsen, H. and Vernooy-Dassen, M. 2004. Kwalitatief onderzoek: nuttig, onmisbaar en uitdagend. Huisarts en wetenschap. 47, 10 (2004), 288-292. DOI:https://doi.org/10.1007/BF03083760.

[43] Punch, K.F. 2013. Introduction to social research: Quantitative and qualitative approaches. sage.

[44] Rapley, T. 2018. Doing conversation, discourse and document analysis. Sage.

[45] Strauss, A. and Corbin, J. 1998. Basics of qualitative research techniques. Citeseer.

[46] tasmu.gov.qa: 2018. https://www.tasmu.gov.qa/en. Accessed: 2021-04-10.

[47] Twizeyimana, J.D. and Andersson, A. 2019. The public value of E-Government - A literature review. Government Information Quarterly.

[48] UNDESA - United Nations Department of Economic and Social Affairs 2020. Compendium of Digital Government Initiatives in response to the COVID-19 Pandemic.

[49] UNDESA - United Nations Department of Economic and Social Affairs 2018. United Nations E-Goverment Survey 2018: Gearing E-Goverment to Support Trasnformation towards Sustainable and Resilient Societies.

[50] Weerakkody, V. 2007. Exploring e-government in the state of Qatar: Benefits, challenges and complexities. (2007).

[51] Weerakkody, V. et al. 2011. Exploring the complexities of e-government implementation and diffusion in a developing country: Some lessons from the State of Qatar. Fournal of Enterprise Information Management. 24, 2 (2011), $172-196$.

[52] World Bank Country Profile - Qatar: 2020. https://databank.worldbank.org/views/reports/reportwidget.aspx?Report_Nam $\mathrm{e}=$ CountryProfile $\& I d=b 450 f d 57 \&$ tbar $=y \& d d=y \& i n f=n \& z m=n$. Accessed: 2021 04-10.

ةنقاك قنلاو 2020 ربمسيد / ل و ولأام

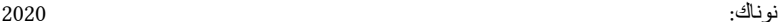
https://www.unescwa.org/sites/www.unescwa.org/files/publications/files/gove rnment-electronic-mobile-services-gems-2020-arabic_0.pdf.

تلا قنلاو 2020 ربمسيد / ل و لأا م نوناك: https://www.unescwa.org/sites/www.unescwa.org/files/publications/files/gove rnment-electronic-mobile-services-gems-2020-arabic_0.pdf. 